The instrument will also be made more compact by the use of an altazimuth mount. Most large telescopes have been mounted with their axis of rotation parallel to that of the Earth, so that only one sweeping movement is required to track an object across the sky, but this so-called equatorial mount is relatively bulky. The advent of computer control has now removed the obstacles that once prevented use of the smaller but more complex altazimuth mount, which requires coordinated rotation about both the vertical and horizontal axes.

For either the thin continuous mirror or the segmented mirror, the question of how to evenly distribute the weight of the glass raises a host of unsolved problems. In either case 'active optics' will be required-that is, the stress on various support points must change continuously to prevent deformation of the glass when the mirror is tilted. The thin monolithic mirror would require some 100 to 200 support points, the majority of which must be active. On the other design, each segment of the composite mirror would require 12 sensors and 3 actuators to change its tilt and focus. On this point, at least, Nelson seems confident. "We think control is no problem," he says. A simple actuator device for segments of the composite mirror has already been tested and shown to be many times more precise than required, and the overall control scheme has been successfully modelled on a computer.

Preparing the glass, however, is another matter. A leading glass company has agreed to prepare the monolithic blank if that design is finally chosen, but many problems would remain in caring for the world's largest piece of fragile glassware. Among other things, the whole mirror, planned to be only 15 centimetres thick,

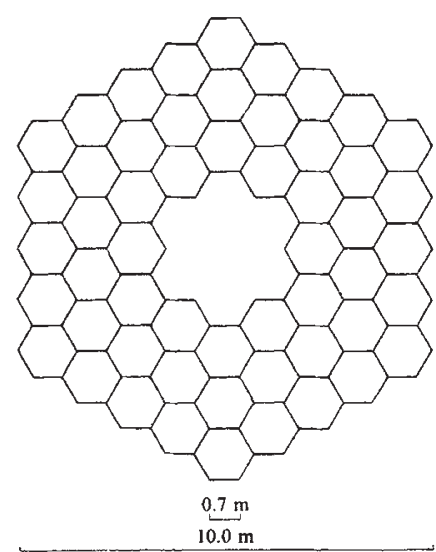

Possible segmented design for $10 \mathrm{~m}$ mirror

would have to be enclosed in a vacuum tank each year for realuminizing. The segmented mirror also under consideration would require nine basic segment shapes to produce an overall parabolic curvature. The polishing might be done by computer control on segments already prepared for mounting, or possibly by a cheaper method-which Nelson calls "extremely promising"-in which the pre-stressed segments are polished spherically then released to snap back into the shape of an off-axis parabola. The ten centimetre thick segments would be hexagonal, 0.7 metres on a side, and mounted in three rings around a larger central mirror. The completed composite mirror would contain 54 segments.

The final cost should be in the range of $\$ 20-50$ million, of which the university hopes to raise at least half initially and then try to obtain matching federal funds. If construction can begin by 1981 the new telescope might be completed by 1986 .

To avoid as much water vapour as possible, three relatively arid mountains have been proposed as possible sites. Mauna Kea, a 14,000 foot volcano in
Hawaii, would be the most accessible since the roads already lead to existing observatories on its peak. White Mountain in California, also 14,000 feet high, would be closer to the university's campuses, but the summit is almost unreachable by land vehicle: Junipero Serra Mountain is close to the UC Santa Cruz campus, which has a particularly active astronomy department, but with a height of only 6,000 feet it is by far the most moist of the three locations. Wherever the new observatory is built, the planners have already resigned themselves to building a structure sturdy enough to allow observations in the midst of $50 \mathrm{mph}$ winds.

NeIson and others involved in the project sound optimistic about being able to build their proposed observatory, despite its high cost and necessarily radical design. They point out four broad classes of observation that would be facilitated by the proposed instrument:

- With direct optical imaging, a 10metre telescope would permit better study of distant galaxies and a further attack on the problem of whether the universe will expand for ever or eventually collapse.

- Direct infrared observations would be used to study protostars and the structure of the galactic centreperhaps resolving the question of whether it contains a massive black hole.

- Optical spectroscopy using the new instrument would allow astronomers to study globular clusters around other galaxies and investigate why quasars have absorption lines.

- Finally, infrared spectroscopy could be used to determine the abundances of various molecules in stars, and to study the emission spectra of quasars.

John Douglas

\title{
Sussex students step up science exam protest
}

Protest escalated last week at the campus of Sussex University against a compulsory first-year preliminary science examination. Two students, Richard Flint, president of the student union and Shaun Fensom, an engineering student, were "excluded permanently" from campus by viceChancellor Sir Denys Wilkinson for their "leadership" of a student-unionmandated disruption of a resitting of the contested examination.

An emergency Senate meeting has been called for 13 June when the ViceChancellor will explain his action to the faculty.

Half the university's 4,000 students attended an emergency meeting on 5 June. They rejected a call for an immediate occupation of university buildings, but voted to canvass university and staff to protest against the expulsion and seek support from campus trade unions. They also decided on a series of one-day strikes the first of which was held last Friday with mass picketing at university entrances. The vice-chancellor was turned away. Students estimated that attendance was reduced to $10 \%-20 \%$ of normal but administration officials claimed that the action had not achieved its aim of stopping all classes.

The protest is taking a form not familiar since the $1960 \mathrm{~s}$. The original campaign began two years ago when the student union voted for direct student action to end a compulsory first-year examination in science subjects. The science division is the only one at Sussex with such a requirement. Arguing that the exam distorted teaching practices and served no useful assessment purpose, the union called for a boycott. In the first year the boycott was $65 \%$ effective.

In the meantime a nine-member faculty working party was set up to consider the students' demand. It rejected the students' proposal that the exam be made optional, citing a need for "rigorous training in discipline", "an ability to marshal facts under pressure and to meet deadlines" and the "necessity for an objective means to monitor progress" as reasons for its decision. The working party specifically 
rejected the students' request for tutorial assessment.

Students maintained their position, arguing that skill at examinations is unrelated to the skills it takes to be a competent scientist and that gearing the course towards quantitative assessment actually reduced learning. In January, a second boycott was called, with the addition that any resitting of the exam that included boycotters would be disrupted.

The second boycott was far less successful with only $10 \%$ of the students failing to attend. Nevertheless the university rescheduled the exam to include students who had participated in the boycott. The exam was disrupted by 25 students who occupied the room. A second resitting was re- scheduled, this time with faculty, police and photographers in attendance, but the students banged on tin cans and drums outside the examination room.

On 1 June, the two students were summoned to the vice-chancellor's office and expelled for their part in the disturbances.

Joe Schwartz

\section{Soviets get their fun from learning about science}

SovieT society is in many ways surprisingly Victorian-a trend shown in the great popularity of the scientific lecture as a form of cultural entertainment. The organisation of such lectures is the task of the Znanie (Knowledge) Society, founded in 1947, which, in Soviet society, plays roughly the role of the British Association for the Advancement of Science, the Royal Institution, and the Worker's Educational Association in the United Kingdom.

Recently, two notable ropresentatives of Znanie, Nobel Laureate Academician Basov and Dr Vladislavev, toured the UK as part of the "Days of Soviet Science and Technology" organised in connection with the Soviet Exhibition at Earls Court. A delegation of 11 scientists and some 10 support personnel took part in the "Days". The host was the British Association-although, by some failure in communication, they were not aware until the delegation arrived of the great significance which Soviet science publicity puts on the organisation of such "Days". Nevertheless. one outcome of the visit was agreement to exchange lecturers between Znanie and the British Association --although it seems unlikely that the Soviet public will have the direct benefit of words of wisdom from the BA in the foreseeable future.

For Znanie, although lauded in official handbooks as being built on "democratic principles", is a hierarchical organisation. Although the society is supposed to organise lectures for any Soviet collective farm, factory or club that demands them, it would be impractical for top-flight lecturers to be constantly commuting, say, between Moscow and Vladivostok. "What we do", explained Vladislavlev "is to organise lectures for lecturers" in such remote places. Then the lecturers we have trained can give lectures at the local level".

If a top specialist is required, then the organisation requesting him must pay his fare. This suggests that the remote areas are somewhat dis- advantaged-an idea which the visitors resolutely denied. As far as the Virgin Lands, and the far north of Siberia are concerned, they explained, there are special funds-and for the rest, there are no problems. Local lecturers are well trained to do their job in popularising science.

Lecturers, in fact, form the only 'members' of Znanie (apart from administration personnel). The main privilege of membership is to give frequent lectures (usually gratis) to whatever audience demands your services, and to attend frequent seminars on the latest developments in your field and the newest methods of lecturing. "The main problem", Vladislavlev explained, "is to make lectures appropriate for different audiences. 'That is why it is obligatory, when you ask for a lecturer, to describe the intended audience."

Not all lectures are simply a cultural diversion. Znanie is also responsible for the 'People's Universities', a fairly now feature of Soviet life. Courses are organised by plants and ministries to provide workers with the means of improving their professional qualifications.

Znanie itself is only concerned with the academic side-it is up to the factory commissioning its services to provide the facilities and to organise funding. Some $60 \%$ of Znanie funds, he added, come from non-state sources-factories, and trade unions. Of course, if a worker simply want to study, say, English Literature, he added, "then he pays for himself, just as if he was going to the cinema!"

To the Soviet mind, 'science' implies, as Academician Basov put it, "all advances in knowledge". Thus the 'flow-diagram' of Znanie's work includes 'Houses of atheism' in parallel with its planetaria. The most popular lectures organised by the society, according to Vladislavlev, are those on international affairs, followed by medicine.

Only the lecturers and organisers, not the audiences, are members of Znanie. If, say, some Ukrainian collec- tive-farm wants to start a 'Birdwatchers' club', Znanie will provide lecturers and suggest reading matter, but the club cannot become an associate member of Znanie. Only highlevel professional societies, such as the "Popov Radio-technical Society" has that privilege. (Some 40 such societies at present are 'collective members' of Znanie.)

Even so, with more than three million active members (lecturers and paid local organisers), there is no need to invite further people to join. "We have too many members already", Basov said. Some prominent personalities, of course, are virtually ex officio members. All Soviet cosmonauts, said Vladislavlev, are exploited enormously. "In fact, their bosses are always telling us to leave them in peace to get on with their job."

"There is an increasing demand for scientific knowledge and an increasing interest" said Vladislavlev. "The more one knows, the more one wants to know." As for the social impact of science, Academician Basov reiterated an earlier communication to the British Association that "science is not always good!" It would appear, however, that, in spite of a vast quantity of general science reporting (all major discoveries are reported in Pravda, Basov said), the Soviet public have not developed a "doomwatch outlook".

"It is not disasters that interest the public in science", said Vladislavlev, referring to Harrisburg. "The interest comes naturally from the rising cultural level."

And, as far as the Soviet citizen is concerned, everything is done to encourage that rise. "First we offer him a single lecture", said Vladislavlev. "Then, having caught his interest, a course of lectures. And finally, enrolment in a Pcople's University. We are concerned in what you would call continuous adult education, and its development is our main task for the future!"

Vera Rich 